\title{
Short stature homeobox 2 methylation as a potential noninvasive biomarker in bronchial aspirates for lung cancer diagnosis
}

\author{
Shumin $\mathrm{Ni}^{1}$, Meng $\mathrm{Ye}^{1}$ and Tao Huang ${ }^{1}$ \\ ${ }^{1}$ The Affiliated Hospital of Ningbo University, Ningbo, Zhejiang 315020, People's Republic of China \\ Correspondence to: Tao Huang, email: huangtao334@163.com \\ Meng Ye, email: yemeng@nbu.edu.cn \\ Keywords: methylation, SHOX2, lung cancer, bronchial aspirates, diagnosis \\ Received: February 15, $2017 \quad$ Accepted: April 25, $2017 \quad$ Published: May 22, 2017 \\ Copyright: $\mathrm{Ni}$ et al. This is an open-access article distributed under the terms of the Creative Commons Attribution License 3.0 \\ (CC BY 3.0), which permits unrestricted use, distribution, and reproduction in any medium, provided the original author and source \\ are credited.
}

\section{ABSTRACT}

Gene methylation has been frequently observed in lung cancer. However, the use of methylated genes in bronchial aspirates of patients with lung cancer remains to be evaluated. The purpose of this study was to analyze whether the detection of genes with aberrant promoter methylation can be useful noninvasive biomarkers in bronchial aspirates from lung cancer. We found that the methylation status of the cyclin-dependent kinase inhibitor 2A (P16), Ras association domain family 1 isoform (RASSF1A), adenomatous polyposis coli (APC) and short stature homeobox 2 (SHOX2) genes was significantly correlated with lung cancer in bronchial aspirates. The P16, RASSF1A and APC methylation had a bad diagnostic effect in bronchial aspirates of patients with lung cancer compared with non-tumor controls ( $P$ 16: sensitivity = 0.26 , specificity $=0.99$, area under the curve $(A U C)=0.67 ;$ RASSF1A: sensitivity $=$ 0.40 , specificity $=0.99$, AUC $=0.66 ;$ APC: sensitivity $=0.17$, specificity $=0.98$, AUC $=0.65)$. The pooled sensitivity, specificity, and AUC of the SHOX2 methylation were $0.75,0.94$, and 0.94 , respectively. Moreover, when squamous cell carcinoma (SCC) was compared to adenocarcinoma (AC), the SHOX2 gene had a significantly higher methylation rate in SCC than in AC $(P<0.001)$. Methylated P16, RASSF1A, APC and retinoic acid receptor beta 2 (RARß2) genes had similar frequencies in these two histotypes $(P>0.1)$. Our findings suggest that methylated $5 H O X 2$ gene could be a specific and potential noninvasive biomarker using bronchial aspirates for lung cancer diagnosis, especially for SCC.

\section{INTRODUCTION}

Lung cancer is the most common human malignant tumor and causes the highest number of cancer-related deaths worldwide. On the basis of global cancer statistics, approximately $1,824,700$ new patients with lung cancer were diagnosed, leading to an estimated 1,589,900 deaths in 2012 [1]. Lung carcinoma encompasses non-small cell lung cancer (NSCLC) and small cell lung cancer (SCLC). The former accounts for approximately $85 \%$ of cases of lung cancer, mainly consisting of adenocarcinoma (AC) and squamous cell carcinoma (SCC) $[2,3]$.
Accumulating evidence has shown that DNA methylation, a major molecular mechanism of epigenetic changes, is correlated with human malignant tumors, including lung cancer [4-7]. Genes with aberrant DNA methylation can be noninvasive biomarkers for the detection and diagnosis of cancer [8-10]. Methylated genes were found in body fluid samples, such as plasma, urine, sera, and sputum, indicating that DNA methylation had the potential value as a biomarker in non-invasive cancer screening and diagnosis [11-13].

$P 16$, consisting of an alternative reading frame of cyclin-dependent kinase inhibitor $2 \mathrm{~A}$ (CDKN2A), is thought to function as a tumor suppressor by negatively 
regulating the cell cycle and inhibiting cell proliferation $[14,15]$. RASSF1A (Ras association domain family 1 isoform) could lead to tumourigenesis associated with the regulation of the cell cycle, apoptosis, migration and adhesion [16, 17]. The adenomatous polyposis coli $(A P C)$ gene encodes a large multidomain protein and its dysfunction participates in tumor development [18, 19]. The human homeobox gene $\mathrm{SHOX} 2$ (short stature homeobox 2) as a regulator affects skeletal, heart and nervous system development, along with embryonic morphogenesis $[20,21]$. A large number of genes are shown to be frequently methylated in tissue specimens in lung cancer, including $P 16, R A S S F 1 A, A P C$ and $M G M T$ $[22,23]$.

However, DNA methylation-based biomarkers using bronchial aspirates in non-invasive lung cancer detection remain to be identified. Hence, we performed the present analysis of a list of genes with aberrant DNA methylation to provide molecular clues in bronchial aspirates for the detection and diagnosis of lung cancer.

\section{RESULTS}

\section{Characteristics of the included studies}

As depicted in Figure 1, on the basis of the inclusion criteria, final 21 eligible studies involving 20 genes were evaluated in bronchial aspirates in lung cancer [24-44]. Of these genes, four genes with more than three studies evaluated the relationship between the methylation status of the P16, RASSF1A, APC and SHOX2 genes and lung cancer. The remaining 16 genes were also assessed in fewer than four studies in the current study. The general characteristics of the studies of eligibility are presented in Supplementary Table 1.

\section{Aberrantly methylated genes in bronchial aspirates in lung cancer}

The results from bronchial aspirates showed that a significant correlation was observed between the methylation of the $P 16(\mathrm{OR}=8.15,95 \% \mathrm{CI}=3.18$ - 20.87, $P<0.001), R A S S F 1 A(\mathrm{OR}=32.60,95 \% \mathrm{CI}=$ $19.21-55.32, P<0.001), A P C(\mathrm{OR}=11.88,95 \% \mathrm{CI}=$ $4.75-29.72, P<0.001)$ and SHOX2 (OR $=50.10,95 \%$ $\mathrm{CI}=30.30-82.84, P<0.001)$ genes with lung cancer in more than four studies, including 840 lung cancer patients and 800 controls (Figure 2), 980 lung cancer patients and 733 controls (Figure 3), 360 patients with lung cancer and 273 controls (Figure 4), and 493 patients with lung cancer and 415 controls (Figure 4), respectively.

For analyses with less than four studies on the remaining 16 genes, the methylation frequency of nine genes was significantly higher in bronchial aspirates of patients with lung cancer than in controls without cancer (Supplementary Table 2).

\section{Subgroup analyses of the P16 and RASSF1A methylation}

We conducted subgroup analyses regarding the P16 and RASSF1A genes to find variations in different ethnicities (Asians and Caucasians) and detection methods (methylation specific PCR (MSP) and quantitative methylation specific PCR (QMSP)) (Table 1).

The subgroup analysis by ethnic population showed that P16 methylation was significantly correlated with lung cancer in the Caucasian and Asian populations $(\mathrm{OR}=6.32$, $P=0.01$ and $\mathrm{OR}=11.65, P<0.001$, respectively). Based on the detection method of methylation, a significant association was found between P16 methylation status and lung cancer in the MSP and QMSP subgroups (OR = $4.49, P<0.001$ and $\mathrm{OR}=46.43, P<0.001$, respectively).

RASSF $1 A$ methylation was found to be significantly associated with lung cancer in the subgroups of the different detection methods (MSP: OR $=17.01, P<$ 0.001 and QMSP: OR $=44.33, P<0.001)$. The subgroup analysis of ethnicity demonstrated that the methylated RASSF1A gene was significantly associated with lung cancer in Caucasians and Asians $(\mathrm{OR}=40.13, P<0.001$ and $\mathrm{OR}=18.89, P<0.001$, respectively).

\section{Sensitivity analysis of the P16 methylation}

We performed a sensitivity analysis by deleting an individual study to evaluate the change of the pooled OR and heterogeneity in the analysis of the $P 16$ methylation status with substantial heterogeneity $\left(I^{2}=62.2 \%, P=\right.$ $0.003)$. When we removed two studies by Fraipont 2005 et al., France [34] and Nikolaidis 2012 et al., and UK [27] and re-calculated the overall OR from the remaining nine studies, the result demonstrated that the combined OR of the $P 16$ methylation was $8.80(95 \% \mathrm{CI}=5.08-15.23)$, while heterogeneity was dramatically decreased $\left(I^{2}=\right.$ $33.3 \%, P=0.151)$.

\section{Aberrantly methylated genes in tumor histotypes}

We further determined whether the methylation of the P16, RASSF1A, APC, SHOX2 and RAR $\beta 2$ genes in the current study showed different methylation characters in SCC vs. AC and NSCLC vs. SCLC.

When SCC was compared to AC (Figure 5), our results showed that a significant correlation was observed between the methylation of the SHOX2 gene and tumor histology, and its methylation frequency was significantly higher in $\mathrm{SCC}$ than in $\mathrm{AC}(\mathrm{OR}=4.32,95 \% \mathrm{CI}=2.50$ - 7.46, $P<0.001)$. However, no significant relationship was found between P16, RASSF1A, APC or RAR $\beta 2$ methylation and these two histotypes $(P>0.1)$.

When NSCLC was compared to SCLC (Figure 6), our results demonstrated that the methylation of the $P 16$, RASSF $1 A, A P C$ and $S H O X 2$ genes was significantly correlated with tumor histology, and the methylation levels 
of the SHOX2 and RASSF1A were significantly lower in NSCLC than in SCLC $(\mathrm{OR}=0.19,95 \% \mathrm{CI}=0.07-0.49, P$ $=0.001$; and $\mathrm{OR}=0.06,95 \% \mathrm{CI}=0.03-0.13, P<0.001$, respectively). The methylation rate of the $P 16$ and $A P C$ genes was notably higher in NSCLC than in SCLC (OR = $8.36,95 \% \mathrm{CI}=2.37-29.51, P=0.001$ and $\mathrm{OR}=3.60,95 \%$ $\mathrm{CI}=1.54-8.39, P=0.003$, respectively). No significant association was observed between $R A R \beta 2$ methylation and tumor histology in NSCLC vs. SCLC $(P=0.084)$.

\section{Diagnostic effect of methylated P16, RASSF1A, $A P C$ and $S H O X 2$ genes in lung cancer}

This study was also conducted to further assess the diagnostic capacity of $P 16, R A S S F 1 A, A P C$ and $S H O X 2$ methylation status as non-invasive biomarkers in bronchial aspirates. When lung cancer was compared to non-tumor controls in bronchial aspirates, the methylation of the P16 gene in bronchial aspirates from lung cancer patients vs non-tumor bronchial aspirates had a sensitivity value of 0.26 (95\% CI: 0.16-0.39), a specificity value of 0.99 (95\% CI: 0.92-1.00), and an AUC value of 0.67 (95\% CI: 0.63-0.71) (Supplementary Figures 1-3). Methylated RASSF $1 A$ gene had a sensitivity value of $0.40(95 \% \mathrm{CI}$ : $0.34-0.46)$, a specificity value of 0.99 (95\% CI: $0.95-$ $1.00)$, and an AUC value of 0.66 (95\% CI: 0.61-0.70) (Supplementary Figures 1-3). The overall sensitivity, specificity, and AUC of the $A P C$ methylation status were 0.17 (95\% CI: 0.10-0.27), 0.98 (95\% CI: 0.94-0.99), and 0.65 (95\% CI: 0.61-0.69), respectively (Supplementary Figures 1-3). The pooled sensitivity, specificity, and AUC of the SHOX2 methylation status were $0.75(95 \%$ CI: 0.63-0.84), 0.94 (95\% CI: 0.90-0.97), and 0.94 (95\% CI: 0.92-0.96), respectively (Figure 7). The sensitivity value was poor for $P 16, R A S S F 1 A$ and $A P C$ methylation (sensitivity $<0.5)$, while $S H O X 2$ methylation had a good sensitivity value (sensitivity $=0.75>0.5$ ). The above analyses demonstrated that the methylation of the SHOX2 gene could be a potential noninvasive biomarker based on bronchial aspirates in diagnosing lung cancer.

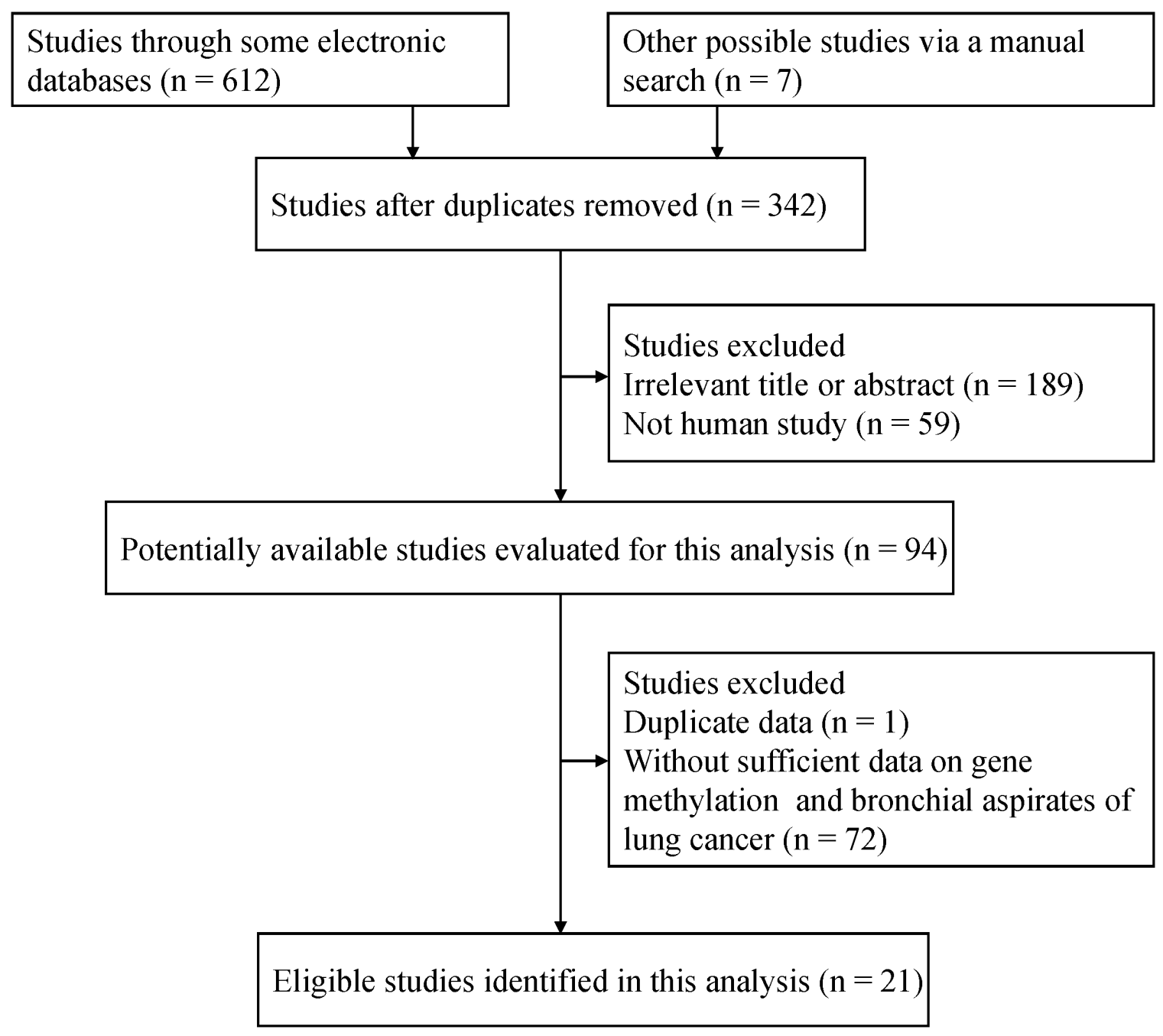

Figure 1: Flow diagram of the relevant literature search strategy. 


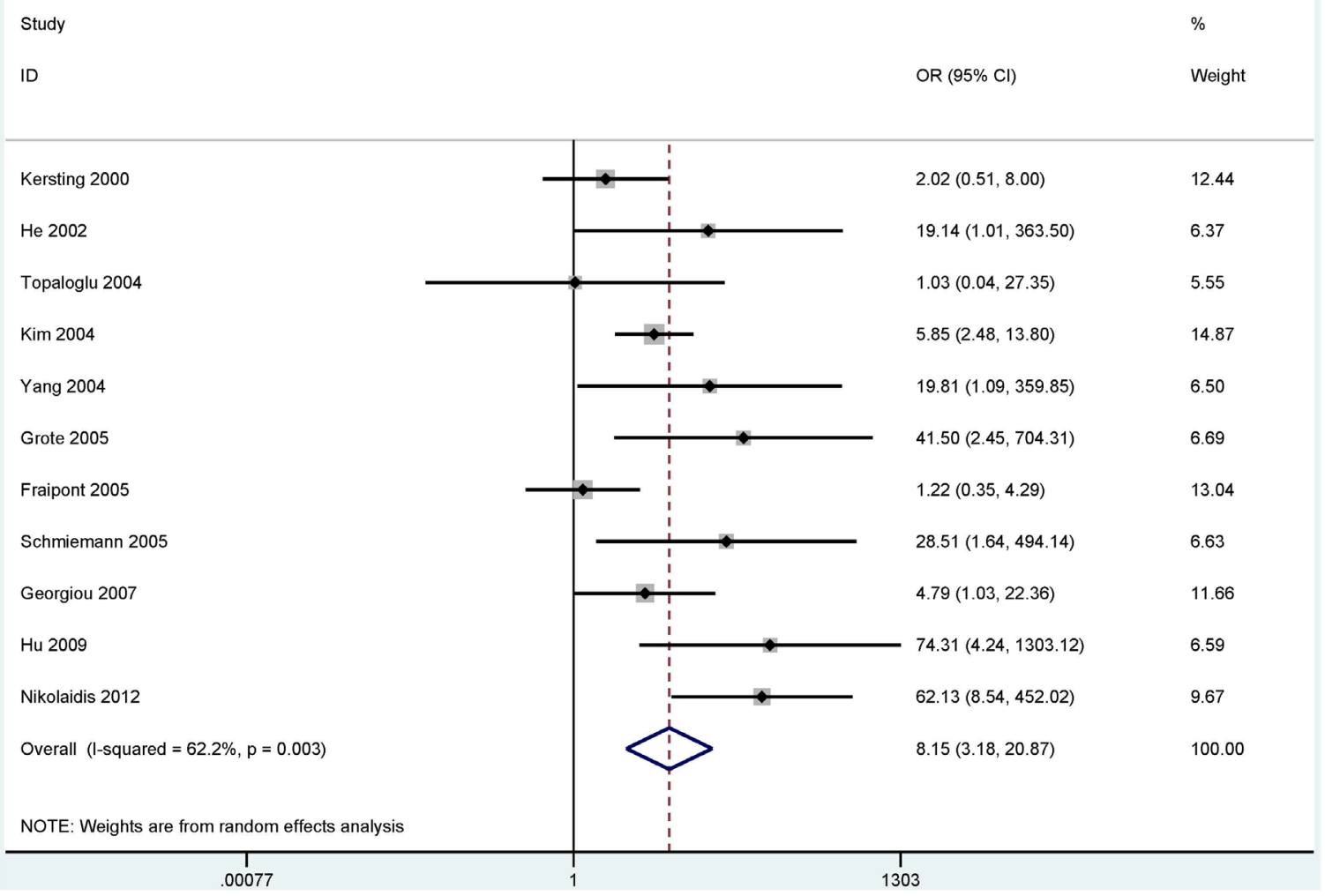

Figure 2: Forest plot showing the pooled OR between $P 16$ methylation and lung cancer in bronchial aspirates $(840$ lung cancer patients and 800 controls). $\mathrm{OR}=8.15,95 \% \mathrm{CI}=3.18-20.87, P<0.001$.

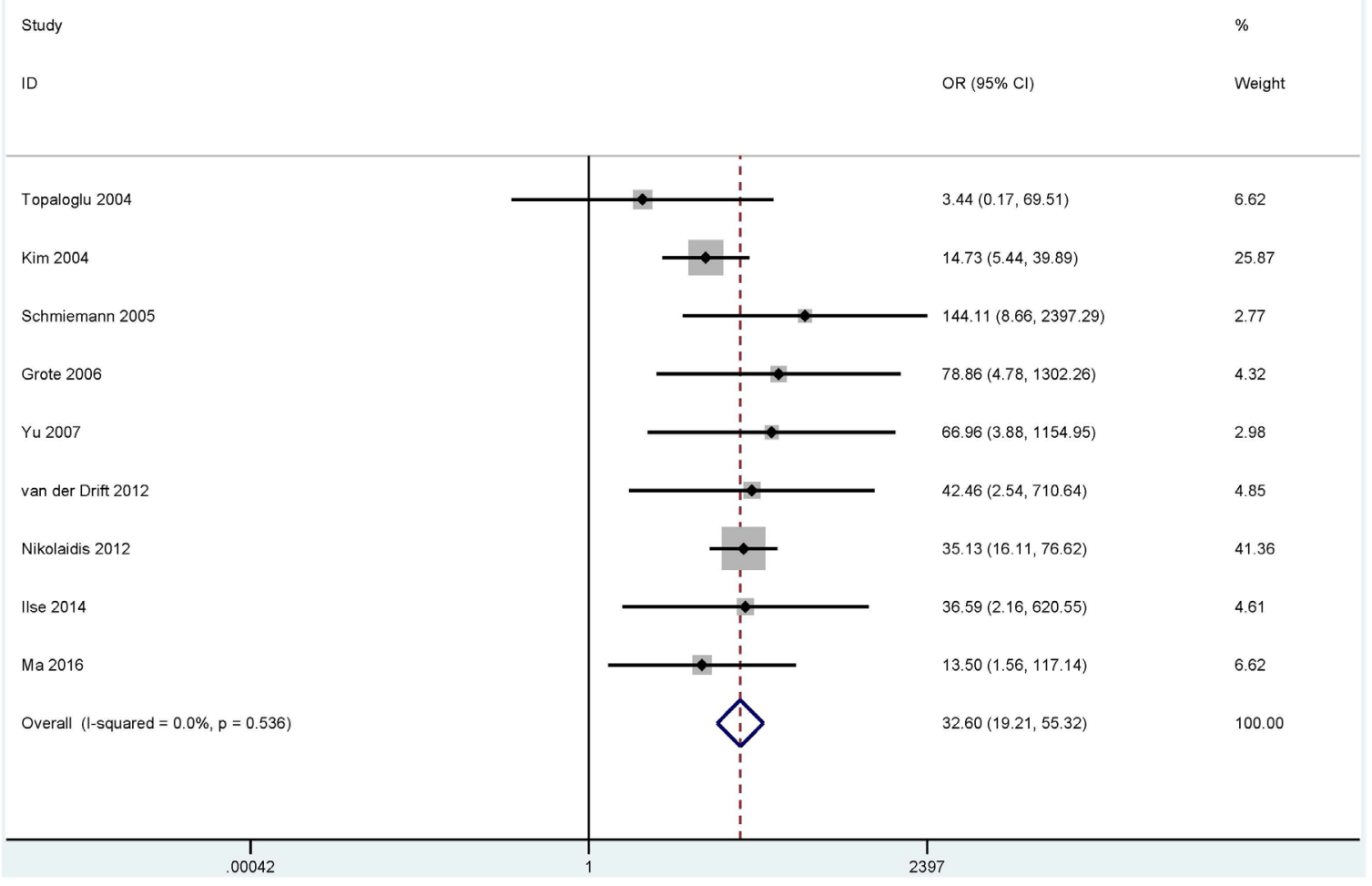

Figure 3: Forest plot showing the pooled $\mathrm{OR}$ between $\mathrm{RASSF1A}$ methylation and lung cancer in bronchial aspirates (980 lung cancer patients and 733 controls). $\mathrm{OR}=32.60,95 \% \mathrm{CI}=19.21-55.32, P<0.001$. 


\section{DISCUSSION}

Aberrant promoter methylation of tumor related genes has been reported as a promising noninvasive biomarker based on the use of feces and serum for future cancer detection and diagnosis in clinical practices $[45$, 46]. However, the methylated genes DNA test in samples from bronchial aspirates was not evaluated in lung cancer. A systematic study of epigenetic association publications was conducted to determine whether the use of gene methylation can become a feasible biomarker in bronchial aspirates for lung cancer screening.

Our analysis mainly focused on four tumor suppressor genes in the promoter regions (the $P 16$, RASSF 1A, APC and SHOX2 genes). Reportedly, these four genes are frequently methylated in bronchial aspirates of patients with lung cancer [25, 27, 37]. However, the results with regard to the methylation levels of the P16, RASSF1A, APC and SHOX2 genes in lung cancer and controls are still controversial and varied. Different methylation rates of the $P 16$ gene in bronchial aspirates of lung cancer patients have been shown, with a range from $3.2 \%$ [38] to $74.2 \%$ [31]. Fraipont et al. reported that the methylation frequency of the $P 16$ was similar in bronchial aspirates of lung cancer patients and controls without cancer [34]. The methylation levels were reported to be $28.2 \%$ in bronchial aspirates of lung cancer patients and $6.3 \%$ in controls by $\mathrm{Kim}$ et al. [36]. RASSF1A methylation frequencies ranged from $12.9 \%$ [38] to $60 \%$ [24] in bronchial aspirates of patients with lung carcinoma. Fraipont et al. reported that the $A P C$ gene had a low and similar methylation rate in bronchial aspirates from patients with lung cancer and controls without cancer [34]. On the other hand, $A P C$ had a significantly different methylation level in bronchial aspirates of patients with lung cancer and cancer-free controls (29\% vs. $1.5 \%)$, as shown by Grote et al. [37]. The SHOX2 gene had a notably higher methylation rate in bronchial aspirates of patients with lung cancer than in cancer-free controls [25, $26]$. Based on eligible studies published in full text, the results showed that the methylation of the P16, RASSF 1A, $A P C$ or $S H O X 2$ genes were significantly associated with lung cancer in the bronchial aspirates, suggesting that the test of methylated P16, RASSF1A, APC or SHOX2 using bronchial aspirates could serve as potential noninvasive biomarkers in lung cancer.

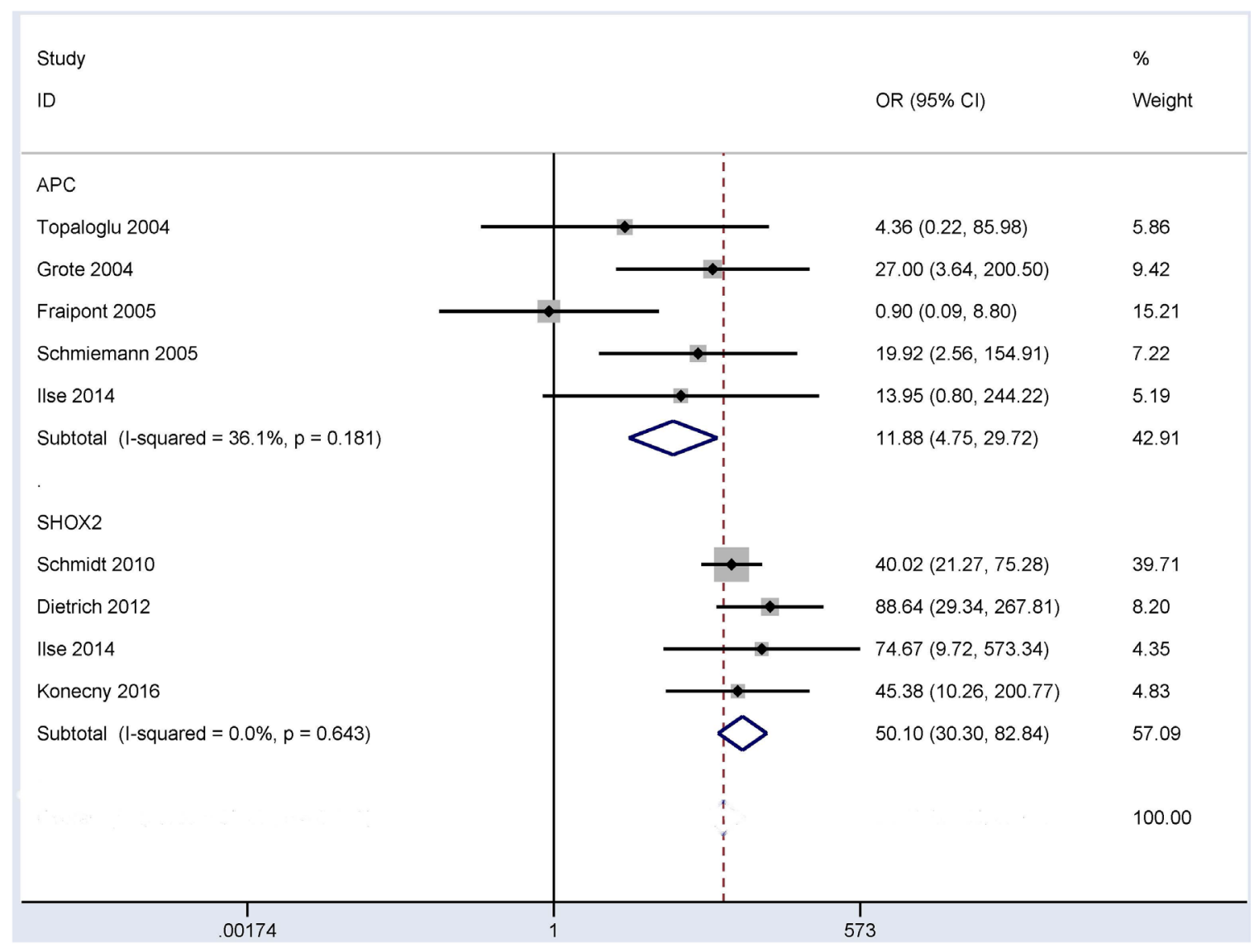

Figure 4: Forest plot indicating the overall OR between $A P C$ (360 patients with lung cancer and 273 controls) and $S H O X 2$ (493 patients with lung cancer and 415 controls) methylation and lung cancer in bronchial aspirates. $\mathrm{OR}=11.88,95 \% \mathrm{CI}=4.75-29.72, P<0.001$ and $\mathrm{OR}=50.10,95 \% \mathrm{CI}=30.30-82.84, P<0.001$, respectively. 
Table 1: Subgroup analyses of methylated $P 16$ and $R A S S F 1 A$ genes

\begin{tabular}{|c|c|c|c|c|c|c|c|}
\hline Gene & Subgroups & Studies & OR $(95 \% \mathrm{CI})$ & $\begin{array}{l}\text { Heterogeneity } \\
\left(I^{2} ; P\right)\end{array}$ & $P$ value & Cases & Controls \\
\hline \multicolumn{8}{|l|}{ P16 } \\
\hline & Ethnicity & & & & & & \\
\hline & Caucasians & 7 & $6.32(1.56-25.53)$ & $72.6 \% ; 0.001$ & 0.01 & 660 & 606 \\
\hline & Asians & 4 & $11.65(3.58-37.95)$ & $25.2 \% ; 0.260$ & $<0.001$ & 180 & 194 \\
\hline & Method & & & & & & \\
\hline & MSP & 8 & $4.49(1.93-10.45)$ & $45.7 \% ; 0.075$ & $<0.001$ & 347 & 312 \\
\hline & QMSP & 3 & $46.43(11.31-190.58)$ & $0.0 \% ; 0.902$ & $<0.001$ & 493 & 488 \\
\hline \multicolumn{8}{|c|}{ RASSF $1 A$} \\
\hline & Ethnicity & & & & & & \\
\hline & Caucasians & 6 & $40.13(20.51-78.54)$ & $0.0 \% ; 0.593$ & $<0.001$ & 810 & 551 \\
\hline & Asians & 3 & $18.89(8.04-44.39)$ & $0.0 \% ; 0.580$ & $<0.001$ & 170 & 182 \\
\hline & Method & & & & & & \\
\hline & MSP & 3 & $17.01(6.93-41.78)$ & $2.8 \% ; 0.358$ & $<0.001$ & 161 & 182 \\
\hline & QMSP & 5 & $44.33(22.23-88.39)$ & $0.0 \% ; 0.878$ & $<0.001$ & 779 & 541 \\
\hline
\end{tabular}

MSP: methylation-specific polymerase chain reaction; QMSP: quantitative methylation-specific polymerase chain reaction; OR: odds ratios; $95 \%$ CI: $95 \%$ confidence interval.

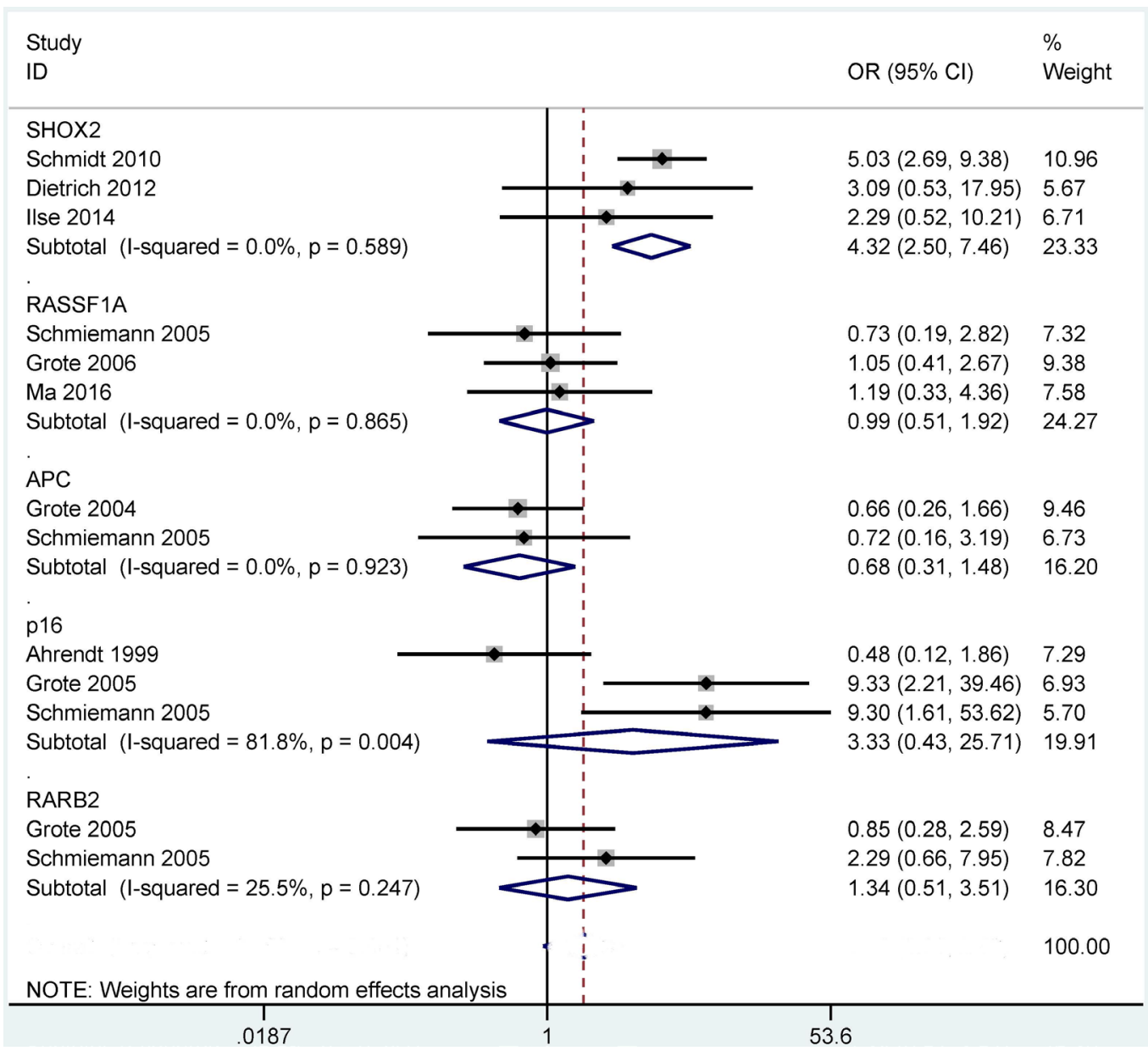

Figure 5: Forest plot indicating the overall OR of the methylation of the P16, RASSF1A, APC, SHOX2 and RARB2 genes between squamous cell carcinoma (SCC) and adenocarcinoma (AC) in bronchial aspirates. $S H O X 2: \mathrm{OR}=4.32$, $95 \% \mathrm{CI}=2.50-7.46, \mathrm{P}<0.001 ; P 16, R A S S F 1 A, A P C$ or $R A R \beta 2(P>0.1)$. 
Some studies have shown that gene methylation can be detected in body fluid samples, such as blood and feces samples, suggesting that tumor suppressor genes with aberrant DNA methylation have the potential to be noninvasive biomarkers that may contribute to the early diagnosis of cancer [45-47]. Hence, we further analyzed the diagnostic capacity of the P16, RASSF $1 A, A P C$ and $S H O X 2$ methylation based on the use of bronchial aspirates in lung cancer. The results demonstrated that the P16, RASSF $1 A$ and APC methylation with low sensitivity $(<0.5)$ and AUC $(<0.8)$ could not distinguish lung cancer and non-tumor samples well. Interestingly, the combined sensitivity, specificity, and AUC values of the SHOX2 methylation were $0.75,0.94$, and 0.94 , respectively, which were very good (sensitivity $=0.75>0.5$, specificity $=0.94$ $>0.9$, and $\mathrm{AUC}=0.94>0.9$ ), indicating that detection of the $S H O X 2$ methylation could be a specific noninvasive biomarker for lung cancer diagnosis using bronchial aspirates.
Although a previous study evaluated the variations between gene methylation and tumor histotypes in the comparison of SCC and AC [48], this meta-analysis did not assess the difference in the bronchial aspirates in these two histotypes. Our findings comparing SCC and AC showed that the $S H O X 2$ methylation was correlated with these two histotypes but not for the P16, RASSF1A, APC and $R A R \beta 2$ methylation. This suggested that the use of the $S H O X 2$ methylation as a biomarker could distinguish SCC and AC, with a significantly higher methylation level in $\mathrm{SCC}$ than in $\mathrm{AC}(\mathrm{OR}=4.32, P<0.001)$. Moreover, in the comparison of NSCLC and SCLC, the methylation status of the $S H O X 2$ gene was correlated with lung cancer histology, indicating that the SHOX2 methylation could contribute to the distinction between NSCLC and SCLC. Meanwhile, the test of the SHOX2 methylation was notably lower in NSCLC than in SCLC (OR $=0.19, P$ $=0.001)$. The above analyses suggest that the detection of the SHOX2 methylation may become a specific and

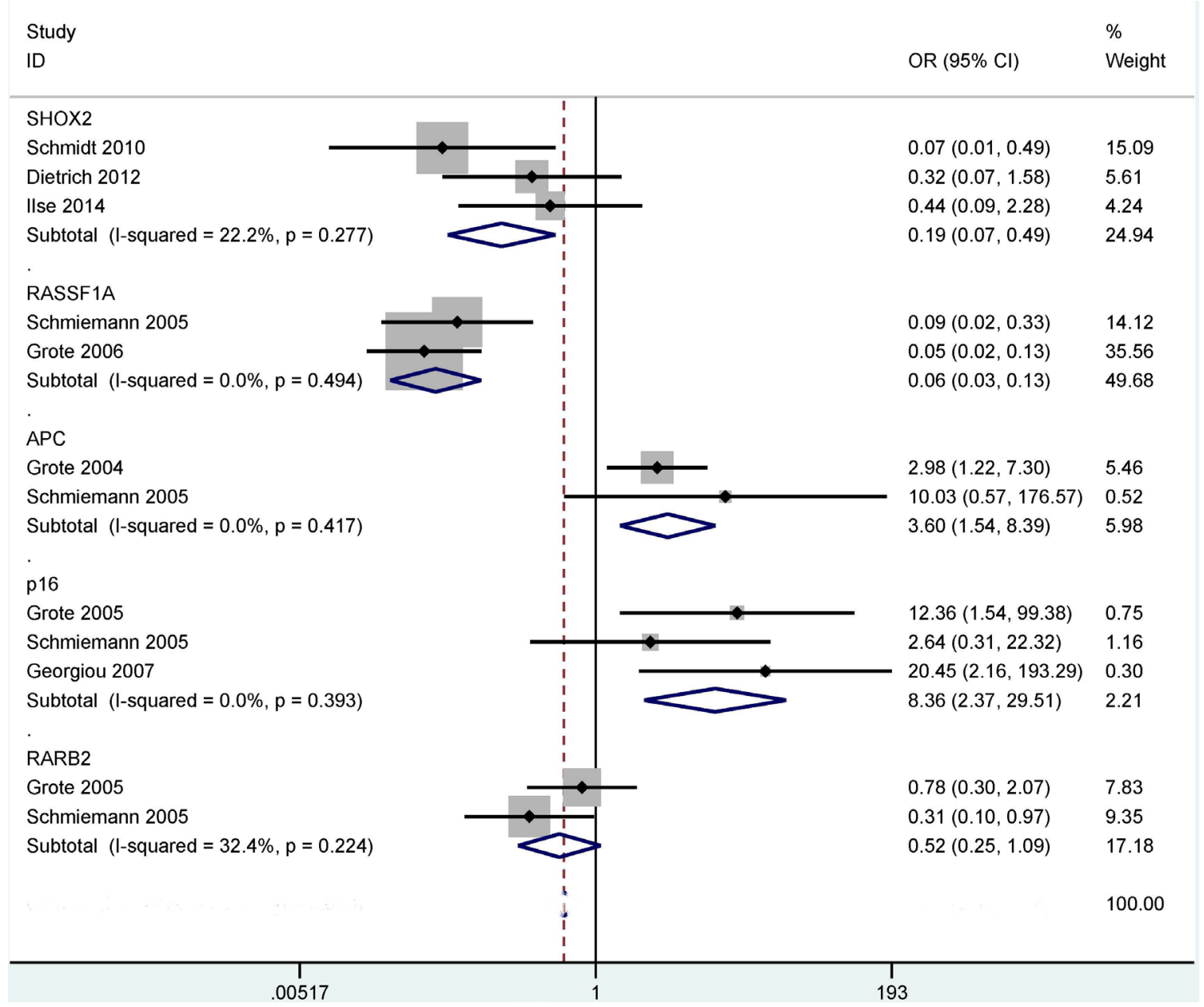

Figure 6: Forest plot showing the combined OR of the methylation of the P16, RASSF1A, APC, SHOX2 and RARB2 genes between non-small cell lung cancer (NSCLC) and small cell lung cancer (SCLC) in bronchial aspirates. $S H O X 2$ : $\mathrm{OR}=0.19,95 \% \mathrm{CI}=0.07-0.49, P=0.001 ; R A S S F 1 A: \mathrm{OR}=0.06,95 \% \mathrm{CI}=0.03-0.13, P<0.001 ; P 16: \mathrm{OR}=8.36,95 \% \mathrm{CI}=2.37-29.51$, $P=0.001 ; A P C: \mathrm{OR}=3.60,95 \% \mathrm{CI}=1.54-8.39, P=0.003 ; R A R \beta 2: P=0.084$. 
promising noninvasive biomarker for the diagnosis of patients with lung cancer using bronchial aspirates, especially in SCC and SCLC.

When lung cancer patients were compared to controls, a substantial heterogeneity was measured in the $P 16$ gene $\left(I^{2}=62.2 \%, P=0.003\right)$. When we removed two studies [27, 34] and re-calculated the overall OR, the pooled result did not significantly change with an absence of heterogeneity, suggesting the stability of our analysis. In our study, a subgroup analysis of the testing method showed that the P16 methylation was correlated with lung cancer in different methods. The reason of substantial heterogeneity was not very clear, but possible reasons could be inappropriate primers and the condition of detection of the P16 methylation.

The present study had some limitations. First, we searched the abovementioned electronic databases to minimize the potential bias as completely as possible, while only available articles published in English or Chinese were included in this analysis. Publications in languages other than English and Chinese were excluded, and conference abstracts were also excluded due to insufficient data. Second, based on small sample sizes, the results regarding the comparison of the different tumor histotypes should be done to further validate the detection of the SHOX2 gene in lung cancer histology in the future. Third, for the remaining 16 genes with small subjects, further large-scale clinical research with a large sample size is essential in bronchial aspirates. Finally, prospective large-scale studies with sufficient information, such as early and advanced stages of patients with lung cancer in bronchial aspirates, are crucial in future research.

In conclusion, our findings suggest that the $\mathrm{SHOX}$, P16, RASSF1A and APC methylation was associated with lung cancer in bronchial aspirates. The SHOX2 methylation may become a useful noninvasive biomarker for lung cancer diagnosis, but P16, RASSF $1 A$ and $A P C$ methylation showed poor diagnostic effects. Moreover, only SHOX2 methylation was significantly higher in SCC than in AC, but P16, RASSF $1 A$ or APC methylation had a similar level in SCC and AC. Further well-designed (multi-center) and prospective large-scale studies

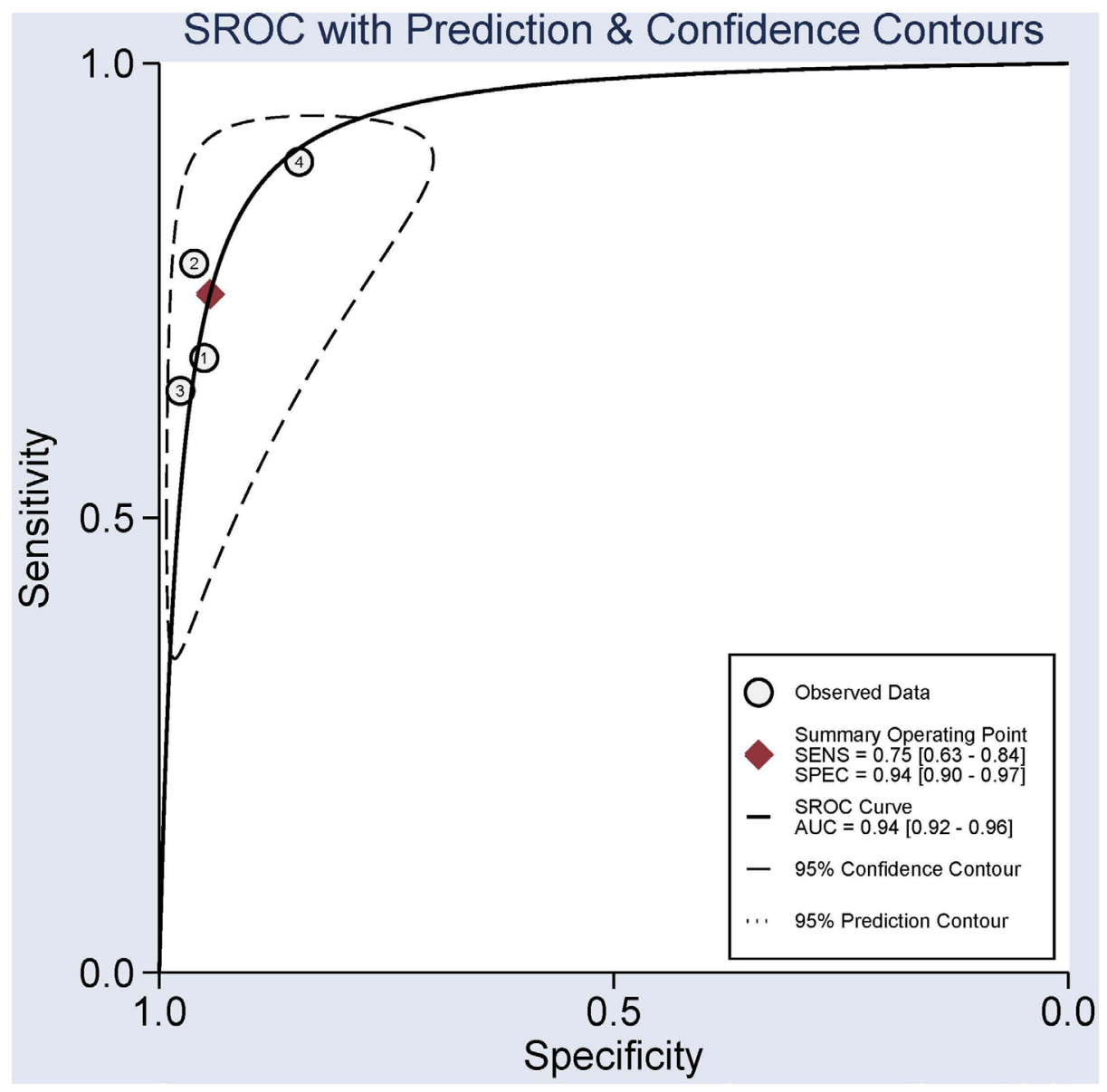

Figure 7: Summary receiver operating characteristics (SROC) evaluation for the potential diagnostic effect of the SHOX2 methylation using bronchial aspirates in lung cancer vs. non-tumor controls. Sensitivity $=0.75(95 \%$ CI: $0.63-0.84)$, specificity $=0.94$ (95\% CI: 0.90-0.97), and area under the curve (AUC) $=0.94(95 \%$ CI: 0.92-0.96), suggesting that SHOX2 methylation was a promising biomarker for lung cancer diagnosis (sensitivity $=0.75>0.5$, specificity $=0.94>0.9$, and $\mathrm{AUC}=0.94>0.9$ ). 
are required to validate the diagnostic value of gene methylation, especially for the SHOX2 gene in bronchial aspirates of lung cancer.

\section{MATERIALS AND METHODS}

\section{Search strategy}

We performed a systematic literature search of the PubMed, Embase, EBSCO, Wanfang, and Cochrane Library databases until October 11th, 2016. The following key words and search terms were used: (lung cancer OR lung tumor OR lung carcinoma OR lung neoplasm) AND (methylation OR hypermethylation OR epigenetic silencing OR epigenetic inactivation) AND (bronchial* OR bronchial washings OR bronchoalveolar lavage OR bronchoalveolar lavage fluid OR BALF OR BAL). We did not apply language restrictions. To obtain other potential publications, the references of the included studies were also manually investigated in this study.

\section{Inclusion criteria}

The selection criteria included the following: 1) patients were diagnosed with lung cancer by histopathology or endoscopy; 2) case-control or cohort design provided sufficient information regarding gene methylation in bronchial aspirates (bronchial washings, bronchoalveolar lavage fluids); and 3) the full texts of all of eligible studies were published in English or Chinese. For the presence of more than one published paper that used duplicated data, only the most recent study with more information was included in the present analysis.

\section{Data collection}

We extracted the following information from eligible studies: the names of the first author, year of publication, country, ethnic population, histology, mean or median age, clinical stage, smoking information, gender status, methodology of the detection of gene methylation, number of case and control groups, frequency of gene methylation, and tumor histotypes. Lung cancer included NSCLC and SCLC types from the original articles in the present study.

\section{Data analysis}

Data were calculated with Stata software (version 12.0, Stata Corporation, College Station, TX, USA). The relationships between gene methylation and lung cancer were evaluated by the combined odds ratios (ORs) and their $95 \%$ confidence interval $(95 \% \mathrm{CI})$. The correlations between gene methylation and tumor histotypes were also determined in this study. The statistical heterogeneity was measured based on the Cochran's Q statistic and
$I^{2}$ test [49]. A $P$ value of $<0.1$ for the Cochrane Q test and an $I^{2}$ value of $>50 \%$ were considered as substantial heterogeneity, and the random-effects model was applied for this meta-analysis; otherwise, a fixed-effects model was used $[50,51]$. To evaluate the influence of an individual study on the pooled results, the omission of one study was performed by sensitivity analysis when significant heterogeneity was tested in genes with more than five studies [52]. Subgroup analyses were carried out to find the differences among the different subgroups. Additionally, according to the bivariate analysis, the pooled sensitivity, specificity, and the summary receiver operator characteristic (SROC) curve (AUC) values were utilized to further evaluate and explore the diagnostic effect of P16, RASSF 1A, APC and SHOX2 methylation in bronchial aspirates of patients with lung cancer. An AUC value was commonly applied to determine the accuracy of the diagnostic test in the meta-analysis [53, 54].

\section{Author contributions}

TH and MY conceived and designed the study. SN and MY contributed to the retrieval of articles, the extraction of data, the calculation of data and the design of the figures and tables. All authors approved the final manuscript.

\section{ACKNOWLEDGMENTS}

This research was supported by grants from the Natural Science Foundation of Zhejiang Province (LY16H160005), the Ningbo Natural Science Foundation (2014A610235), and the Project of the Scientific Innovation Team of Ningbo (2015B11050).

\section{CONFLICTS OF INTEREST}

The authors declare that they have no competing financial interests.

\section{REFERENCES}

1. Torre LA, Bray F, Siegel RL, Ferlay J, Lortet-Tieulent J, Jemal A. Global cancer statistics, 2012. CA Cancer J Clin. 2015; 65:87-108.

2. Pao W, Chmielecki J. Rational, biologically based treatment of EGFR-mutant non-small-cell lung cancer. Nat Rev Cancer. 2010; 10:760-774.

3. Takeda K, Hida T, Sato T, Ando M, Seto T, Satouchi M, Ichinose Y, Katakami N, Yamamoto N, Kudoh S, Sasaki J, Matsui K, Takayama K, et al. Randomized phase III trial of platinum-doublet chemotherapy followed by gefitinib compared with continued platinum-doublet chemotherapy in Japanese patients with advanced non-small-cell lung cancer: 
results of a west Japan thoracic oncology group trial (WJTOG0203). J Clin Oncol. 2010; 28:753-760.

4. Chakravarthi BV, Nepal S, Varambally S. Genomic and epigenomic alterations in cancer. Am J Pathol. 2016; 186:1724-1735

5. Khan SA, Reddy D, Gupta S. Global histone posttranslational modifications and cancer: biomarkers for diagnosis, prognosis and treatment? World J Biol Chem. 2015; 6:333-345.

6. Huang T, Chen X, Hong Q, Deng Z, Ma H, Xin Y, Fang Y, Ye H, Wang R, Zhang C, Ye M, Duan S. Meta-analyses of gene methylation and smoking behavior in non-small cell lung cancer patients. Sci Rep. 2015; 5:8897.

7. Kolla V, Zhuang T, Higashi M, Naraparaju K, Brodeur GM. Role of CHD5 in human cancers: 10 years later. Cancer Res. 2014; 74:652-658.

8. Luttmer R, De Strooper LM, Dijkstra MG, Berkhof J, Snijders PJ, Steenbergen RD, van Kemenade FJ, Rozendaal L, Helmerhorst TJ, Verheijen RH, Ter Harmsel WA, van Baal WM, Graziosi PG, et al. FAM19A4 methylation analysis in self-samples compared with cervical scrapes for detecting cervical (pre)cancer in HPV-positive women. $\mathrm{Br}$ J Cancer. 2016; 115:579-587.

9. Chen ZY, Zhang JL, Yao HX, Wang PY, Zhu J, Wang W, Wang X, Wan YL, Chen SW, Chen GW, Liu YC. Aberrant methylation of the SPARC gene promoter and its clinical implication in gastric cancer. Sci Rep. 2014; 4:7035.

10. Gloss BS, Samimi G. Epigenetic biomarkers in epithelial ovarian cancer. Cancer Lett. 2014; 342:257-263.

11. Parikh RB, Prasad V. Blood-based screening for colon cancer: a disruptive innovation or simply a disruption? JAMA. 2016; 315:2519-2520.

12. Costa-Pinheiro P, Montezuma D, Henrique R, Jeronimo C. Diagnostic and prognostic epigenetic biomarkers in cancer. Epigenomics. 2015; 7:1003-1015.

13. Reis IM, Ramachandran K, Speer C, Gordian E, Singal R. Serum GADD45a methylation is a useful biomarker to distinguish benign vs malignant prostate disease. Br J Cancer. 2015; 113:460-468.

14. Rocco JW, Sidransky D. p16(MTS-1/CDKN2/INK4a) in cancer progression. Exp Cell Res. 2001; 264:42-55.

15. Quelle DE, Zindy F, Ashmun RA, Sherr CJ. Alternative reading frames of the INK4a tumor suppressor gene encode two unrelated proteins capable of inducing cell cycle arrest. Cell. 1995; 83:993-1000.

16. Richter AM, Pfeifer GP, Dammann RH. The RASSF proteins in cancer; from epigenetic silencing to functional characterization. Biochim Biophys Acta. 2009; 1796:114-128.

17. van der Weyden L, Adams DJ. The Ras-association domain family (RASSF) members and their role in human tumourigenesis. Biochim Biophys Acta. 2007; 1776:58-85.
18. Nelson S, Nathke IS. Interactions and functions of the adenomatous polyposis coli (APC) protein at a glance. $\mathrm{J}$ Cell Sci. 2013; 126:873-877.

19. Friedrich A, Kullmann F. [Familial adenomatous polyposis syndrome (FAP): pathogenesis and molecular mechanisms]. Med Klin (Munich). 2003; 98:776-782.

20. Yu L, Liu H, Yan M, Yang J, Long F, Muneoka K, Chen Y. Shox 2 is required for chondrocyte proliferation and maturation in proximal limb skeleton. Dev Biol. 2007; 306:549-559.

21. Blaschke RJ, Monaghan AP, Schiller S, Schechinger B, Rao E, Padilla-Nash H, Ried T, Rappold GA. SHOT, a SHOXrelated homeobox gene, is implicated in craniofacial, brain, heart, and limb development. Proc Natl Acad Sci U S A. 1998; 95:2406-2411.

22. Duppel U, Woenckhaus M, Schulz C, Merk J, Dietmaier W. Quantitative detection of TUSC3 promoter methylation -a potential biomarker for prognosis in lung cancer. Oncol Lett. 2016; 12:3004-3012.

23. Guo M, Alumkal J, Drachova T, Gao D, Marina SS, Jen J, Herman JG. CHFR methylation strongly correlates with methylation of DNA damage repair and apoptotic pathway genes in non-small cell lung cancer. Discov Med. 2015; 19:151-158.

24. Ma Y, Bai Y, Mao H, Hong Q, Yang D, Zhang H, Liu F, Wu Z, Jin Q, Zhou H, Cao J, Zhao J, Zhong X, Mao H. A panel of promoter methylation markers for invasive and noninvasive early detection of NSCLC using a quantum dots-based FRET approach. Biosens Bioelectron. 2016; 85:641-648.

25. Konecny M, Markus J, Waczulikova I, Dolesova L, Kozlova R, Repiska V, Novosadova H, Majer I. The value of SHOX2 methylation test in peripheral blood samples used for the differential diagnosis of lung cancer and other lung disorders. Neoplasma. 2016; 63:246-253.

26. Ilse P, Biesterfeld S, Pomjanski N, Wrobel C, Schramm M. Analysis of SHOX2 methylation as an aid to cytology in lung cancer diagnosis. Cancer Genomics Proteomics. 2014; 11:251-258.

27. Nikolaidis G, Raji OY, Markopoulou S, Gosney JR, Bryan J, Warburton C, Walshaw M, Sheard J, Field JK, Liloglou T. DNA methylation biomarkers offer improved diagnostic efficiency in lung cancer. Cancer Res. 2012; 72:5692-5701.

28. Dietrich D, Kneip C, Raji O, Liloglou T, Seegebarth A, Schlegel T, Flemming N, Rausch S, Distler J, Fleischhacker M, Schmidt B, Giles T, Walshaw M, et al. Performance evaluation of the DNA methylation biomarker SHOX2 for the aid in diagnosis of lung cancer based on the analysis of bronchial aspirates. Int J Oncol. 2012; 40:825-832.

29. van der Drift MA, Prinsen CF, Knuiman GJ, Janssen JP, Dekhuijzen PN, Thunnissen FB. Diagnosing peripheral lung cancer: the additional value of the Ras-association domain family $1 \mathrm{~A}$ gene methylation and Kirsten rat sarcoma 2 
viral oncogene homolog mutation analyses in washings in nondiagnostic bronchoscopy. Chest. 2012; 141:169-175.

30. Schmidt B, Liebenberg V, Dietrich D, Schlegel T, Kneip C, Seegebarth A, Flemming N, Seemann S, Distler J, Lewin J, Tetzner R, Weickmann S, Wille U, et al. SHOX2 DNA methylation is a biomarker for the diagnosis of lung cancer based on bronchial aspirates. BMC Cancer. 2010; 10:600.

31. Georgiou E, Valeri R, Tzimagiorgis G, Anzel J, Krikelis D, Tsilikas C, Sarikos G, Destouni C, Dimitriadou A, Kouidou S. Aberrant p16 promoter methylation among Greek lung cancer patients and smokers: correlation with smoking. Eur J Cancer Prev. 2007; 16:396-402.

32. Grote HJ, Schmiemann V, Geddert H, Bocking A, Kappes R, Gabbert HE, Sarbia M. Methylation of RAS association domain family protein $1 \mathrm{~A}$ as a biomarker of lung cancer. Cancer. 2006; 108:129-134.

33. Schmiemann V, Bocking A, Kazimirek M, Onofre AS, Gabbert HE, Kappes R, Gerharz CD, Grote HJ. Methylation assay for the diagnosis of lung cancer on bronchial aspirates: a cohort study. Clin Cancer Res. 2005; 11:7728-7734.

34. de Fraipont F, Moro-Sibilot D, Michelland S, Brambilla E, Brambilla C, Favrot MC. Promoter methylation of genes in bronchial lavages: a marker for early diagnosis of primary and relapsing non-small cell lung cancer? Lung Cancer. 2005; 50:199-209.

35. Grote HJ, Schmiemann V, Geddert H, Rohr UP, Kappes R, Gabbert HE, Bocking A. Aberrant promoter methylation of p16(INK4a), RARB2 and SEMA3B in bronchial aspirates from patients with suspected lung cancer. Int $\mathrm{J}$ Cancer. 2005; 116:720-725.

36. Kim H, Kwon YM, Kim JS, Lee H, Park JH, Shim YM, Han J, Park J, Kim DH. Tumor-specific methylation in bronchial lavage for the early detection of non-small-cell lung cancer. J Clin Oncol. 2004; 22:2363-2370.

37. Grote HJ, Schmiemann V, Kiel S, Bocking A, Kappes R, Gabbert HE, Sarbia M. Aberrant methylation of the adenomatous polyposis coli promoter $1 \mathrm{~A}$ in bronchial aspirates from patients with suspected lung cancer. Int $\mathrm{J}$ Cancer. 2004; 110:751-755.

38. Topaloglu O, Hoque MO, Tokumaru Y, Lee J, Ratovitski E, Sidransky D, Moon CS. Detection of promoter hypermethylation of multiple genes in the tumor and bronchoalveolar lavage of patients with lung cancer. Clin Cancer Res. 2004; 10:2284-2288.

39. Kersting M, Friedl C, Kraus A, Behn M, Pankow W, Schuermann M. Differential frequencies of p16(INK4a) promoter hypermethylation, p53 mutation, and K-ras mutation in exfoliative material mark the development of lung cancer in symptomatic chronic smokers. J Clin Oncol. 2000; 18:3221-3229.

40. Ahrendt SA, Chow JT, Xu LH, Yang SC, Eisenberger CF, Esteller M, Herman JG, Wu L, Decker PA, Jen J, Sidransky D. Molecular detection of tumor cells in bronchoalveolar lavage fluid from patients with early stage lung cancer. J Natl Cancer Inst. 1999; 91:332-339.

41. Yu Z, Yuan Y, Zhang J, Gao Q, Lv J. Detection of RASSF1A gene promoter hypermethylation in patients with lung cancer. J Clin Intern Med. 2007; 24:23-25.

42. Yang LP, Liu WG, Wang XP, Zhang SL. Detection of p16 gene methylation by methylation-specific PCR and its clinical significance in lung cancer. Chin J Clin Oncol. 2004; 31:441-443.

43. $\mathrm{Hu} \mathrm{ZJ}, \mathrm{Hu} \mathrm{HB}$, Liu DY, Chen YP. Clinical significance of detection of p16 gene methylation in early diagnosis of lung cancer. Chin J Pathophys. 2009; 25:1941-1945.

44. He Y, Zhang S, Yang L, Li S, Tang B. Detection of aberrant methylation of p16 gene in non- small cell lung cancer. Chin J Health Lab Technol. 2002; 12:294-295.

45. Yang Q, Huang T, Ye G, Wang B, Zhang X. Methylation of SFRP2 gene as a promising noninvasive biomarker using feces in colorectal cancer diagnosis: a systematic metaanalysis. Sci Rep. 2016; 6:33339.

46. US Preventive Services Task Force, Bibbins-Domingo K, Grossman DC, Curry SJ, Davidson KW, Epling JW Jr, Garcia FA, Gillman MW, Harper DM, Kemper AR, Krist AH, Kurth AE, Landefeld CS, et al. Screening for colorectal cancer: US Preventive Services Task Force Recommendation Statement. JAMA. 2016; 315:2564-2575.

47. Ye M, Huang T, Ying Y, Li J, Yang P, Ni C, Zhou C, Chen $\mathrm{S}$. Detection of 14-3-3 sigma (sigma) promoter methylation as a noninvasive biomarker using blood samples for breast cancer diagnosis. Oncotarget. 2017; 8:9230-9242. doi: 10.18632/oncotarget.13992.

48. Huang T, Li J, Zhang C, Hong Q, Jiang D, Ye M, Duan S. Distinguishing lung adenocarcinoma from lung squamous cell carcinoma by two hypomethylated and three hypermethylated genes: a meta-analysis. PLoS One. 2016; 11:e0149088.

49. Coory MD. Comment on: heterogeneity in meta-analysis should be expected and appropriately quantified. Int J Epidemiol. 2010; 39:932; author reply 933.

50. Higgins JP, Thompson SG, Deeks JJ, Altman DG. Measuring inconsistency in meta-analyses. BMJ. 2003; 327:557-560.

51. DerSimonian R. Meta-analysis in the design and monitoring of clinical trials. Stat Med. 1996; 15:1237-1248; discussion 1249-1252.

52. Lau J, Ioannidis JP, Schmid CH. Quantitative synthesis in systematic reviews. Ann Intern Med. 1997; 127:820-826.

53. Reitsma JB, Glas AS, Rutjes AW, Scholten RJ, Bossuyt PM, Zwinderman AH. Bivariate analysis of sensitivity and specificity produces informative summary measures in diagnostic reviews. J Clin Epidemiol. 2005; 58:982-990.

54. Jones CM, Athanasiou T. Summary receiver operating characteristic curve analysis techniques in the evaluation of diagnostic tests. Ann Thorac Surg. 2005; 79:16-20. 